\title{
Biogenic silver nanoparticles from Trichodesma indicum aqueous leaf extract against Mythimna separata and evaluation of its larvicidal efficacy
}

\author{
Abdul A. Buhroo ${ }^{1 *}$, Gousul Nisa ${ }^{1}$, Syed Asrafuzzaman ${ }^{2}$, Ram Prasad $^{3}$, Razia Rasheed ${ }^{1}$, \\ Atanu Bhattacharyya ${ }^{4}$ \\ ${ }^{1}$ Section of Entomology, P.G. Department of Zoology, University of Kashmir, Hazratbal, Srinagar, India \\ ${ }^{2}$ Department of Zoology, Utkal University, Vani Vihar, Bhubaneswar, Orissa, India \\ ${ }^{3}$ Amity Institute of Microbial Technology, Amity University Uttar Pradesh, Noida, India \\ ${ }^{4}$ Department of Biomedical Engineering, Nanotechnolgy Section, Rajiv Gandhi Institute of Technology and Research Centre, \\ Cholanagar, R.T. Nagar Post, Hebbal, Bangalore, India
}

Vol. 57, No. 2: 194-200, 2017

DOI: 10.1515/jppr-2017-0026

Received: January 16, 2017

Accepted: June 12, 2017

${ }^{*}$ Corresponding address:

abuhroo@yahoo.com

\begin{abstract}
The present exploration is focused on the bio-fabrication of silver nanoparticles (Ag NPs) using Trichodesma indicum aqueous leaf extract as a reducing agent. The synthesized Ag NPs were productively characterized by UV-vis spectroscopy, XRD, and TEM studies. The photosynthesis of Ag NPs was done at room temperature for $24 \mathrm{~h}$ and at $60^{\circ} \mathrm{C}$. The green synthesis of spherical-shaped Ag NPs bio-fabricated from T. indicum with a face centred cubic structure showed average particle sizes of $20-50 \mathrm{~nm}$, which is inconsistent with the particle size calculated by the XRD Scherer equation and TEM analysis. We further explored the larvicidal efficacy of biosynthesized Ag NPs with leaf extracts of T. indicum against Mythimna separata. The results showed that Ag NPs (20-50 nm) of T. indicum possess good larvicidal activity against $M$. separata with an $\mathrm{LC}_{50}$ of $500 \mathrm{ppm}$. Thus, we can advocate that Ag NPs of 20-50 nm size extracted from $T$. indicum may be considered in the pest management programme of $M$. separata in future.
\end{abstract}

Key words: insect pest control, larvicidal, Mythimna separata, nanoformulation, silver nanoparticles (Ag NPs)

\section{Introduction}

The oriental armyworm, Mythimna separata (Lepidoptera: Noctuidae) is a serious pest of cereals in Asia and Australia (Li et al. 2015). In nature, it has been recorded feeding on 33 plant species and grasses belonging to eight families (Sharma and Davies 1982). This pest has caused grave harm at regular intervals on sorghum (Sorghum bicolor), pearl millet (Pennisetum glaucum), rice (Oryza sativa), maize (Zea mays), wheat (Triticum aestivum) and sugarcane (Saccharum officinarum), because more area is under irrigation, and there have been changes in farming systems due to the introduction of high yielding varieties, increased fertilizer use and continuous cultivation (Rashid et al. 2013; Wang et al. 2015). Yield losses are inflicted mainly by the larval stage and the gregarious behaviour of larvae. Sometimes, their population outbreaks result in complete crop loss (Ishiwaka and Masuda 2008). The occurrence of $M$. separata outbreaks has been attributed to extensive use of fertilizers and manure, trash mulch, drought following rains, floods resulting from heavy rainfall, initiation of migrant populations entering a geographic area, as well as temperature and humidity preceding and also during the outbreaks (Ishiwaka and Masuda 2008; Ensaf et al. 2016). The use of chemical insecticides has been a most important tool for pest control. However, there are serious consequences such 
as intoxication of people and animals, contamination of water, air and soil, which results in residues in food, high persistence in the environment, and resistance in pests. They also have an impact on beneficial insects (Regnault-Roger et al. 2005; Abdallah et al. 2016; Zhu et al. 2016). To prevail over this situation, different forms of insecticides have been advocated.

Recently, nanotechnology has been embraced in the world of pesticides and the processes of insect pest control. It has the potential to revolutionize modern day agriculture (Harper 2010). Plants provide a better platform for nanoparticle synthesis since they are free of toxic chemicals and provide natural capping agents. The use of plant extracts also reduces the cost of microorganisms' isolation and culture media thereby enhancing the cost competitive feasibility over nanoparticle synthesis by microbes (Prasad 2014). Nanostructure materials show unusual physical, chemical and biological properties, which are completely distinct from their bulk materials and individual molecules (Prasad et al. 2014; Bhattacharyya et al. 2016). Nanotechnology includes encapsulation and entrapment of nanoagrochemicals such as nanofertilizers, nanopesticides, nanoherbicides, plant growth stimulating nanoscale biomolecules and other active substances by using polymers, dendrimers, surface ionic attachments etc. (Prasad et al. 2016; Jampilek and Kralova 2016). Moreover, other mechanisms may be used for controlled and slow release of agrochemicals which allow the slow uptake of active ingredients. This in turn reduces the amount of agrochemical application by minimizing input and waste (Chen and Yada 2011). Nanomaterial release arrangement in agriculture is important because of the better solubility and stability to degradation in the environment (Chen and Yada 2011; Chowdappa and Gowda 2013). The nanoscale materials, released from vehicles, increase the effectiveness of the insecticidal properties by binding firmly to the plant surface. They reduce the amount of agrochemicals by preventing run off into the surroundings (Johnston 2010; Chowdappa and Gowda 2013). Nanotechnology can be used for combating plant diseases either by controlled delivery of functional molecules or as a diagnostic tool for disease detection. Several nanoparticles such as nanoporous zeolites, nanocapsules and nanosensors may be used in insect pest suppression (Hallberg 2010). The use of nanoparticles as pesticides is an alternative strategy to combat pests which have become resistant to conventional pesticides. There are very few reports pertaining to the larvicidal activity of silver nanoparticles against insect pests. Therefore, there is a need to explore the use of green silver nanoparticles against pests in order to devise management programmes. Hence, the objective of the present study was to investigate the influence of green nanosilver materials (with different doses) against the second instar larvae of $M$. separata.

\section{Materials and Methods}

\section{Test organism}

Different larval instars of $M$. separata were collected from infested fields in the Srinagar and Budgam districts of Kashmir, India. The culture was maintained in the Entomology Laboratory of the Department of Zoology, University of Kashmir at $24 \pm 2^{\circ} \mathrm{C}$ and relative humidity 60-65\%. Fresh maize leaves (Zea mays) were provided for larval feeding. The second instar larvae were taken from the $\mathrm{F}_{1}$ generation and used for bioassay in the laboratory.

\section{Plant collection}

Fresh, healthy leaves of Trichodesma indicum were collected from the Bharathiar University campus, Coimbatore, India. The T. indicum leaves were washed several times with tap water to remove dust particles and finally rinsed with distilled water. The cleaned leaf material was dried in the shade at room temperature and stored for further use.

\section{Preparation of silver nanoparticles (Ag NPs) solution}

The Ag NPs used in the present study were extracted from T. indicum leaves according to Prabha et al. (2015). Twenty grams of fresh leaves were washed with double distilled water and were transferred to a $500 \mathrm{ml}$ beaker containing $100 \mathrm{ml}$ double distilled water and then boiled for $10 \mathrm{~min}$. The obtained extract was filtered through Whatman No.1 filter paper. Five ml of the plant extract was added to $45 \mathrm{ml}$ of $1 \mathrm{mM} \mathrm{AgNO}_{3}$ solution for reduction into $\mathrm{Ag}^{+}$ions. The appearance of a reddish brown colour indicated the formation of $\mathrm{Ag}$ NPs, which was preliminarily confirmed spectrophotometrically. The reaction mixture was then stored at room temperature for $24 \mathrm{~h}$ for total formation of the nanoparticles. The Ag NPs solution thus obtained was purified by repeated centrifugation at 5,000 rpm for 20 min. The supernatant was discarded and the pellet was dissolved in double distilled water. The Ag NPs were confirmed by colour change.

\section{Characterization of Ag NPs}

The produced nanoparticles were subjected to UV-vis absorption spectra and measured in a $1-\mathrm{cm}$ quartz cuvette using a Shimadzu, UV-3600 spectrophotometer, Japan. XRD (X-ray diffraction) analysis of the prepared nanoparticles was done using a diffractometer with $\mathrm{Cu} \mathrm{Ka}$ radiation operated at $40 \mathrm{kV} / 30 \mathrm{~mA}$. The morphology and size of Ag NPs were investigated using a JEOL-JEM-2100 transmission electron microscope 
(TEM). A sample for TEM study was prepared by placing $0.05 \mathrm{ml}$ of distributed silver solution onto a carbon film, supported on a copper grid followed by solvent evaporation.

\section{UV-visible spectroscopy studies}

The Ag NPs show plasmon resonance at 400 to $450 \mathrm{~nm}$ in the UV-visible spectrum. The UV-visible absorption spectra of synthesized Ag NPs was analysed with a spectrophotometer Shimadzu, UV-3600 (Japan).

\section{X-ray diffraction (XRD) analysis}

The crystalline structure of the synthesized Ag NPs was examined through powder X-ray diffraction using a Rigaku Multiflex X-ray powder diffractometer with $\mathrm{Cu} \mathrm{Ka}$ radiation operating between $10^{\circ}$ and $80^{\circ}$ at the scanning rate of $2^{\circ}$ per minute. The Ag NPs were spread over a glass slide and the solvent was evaporated to form a thin film of Ag NPs for XRD analysis. The crystalline size was calculated using line broadening profile and Debye Scherrer's formula $(D=0.94 \lambda$ / $\mathrm{B} \cos \theta)$.

\section{Transmission electron microscope analysis}

A TEM was used to visualize the morphology of the Ag NPs. TEM grids were prepared by placing $0.05 \mathrm{ml}$ of the Ag NPs solution on carbon-coated copper grids and drying under a lamp. Furthermore, the additional presence of metals in the sample was analyzed with a TEM (JEOL).

\section{Determination of lethal concentration through the Ag NPs}

The lethal concentration of the synthesized nanoparticles (20-50 $\mathrm{nm}$ size) was determined by solutions of a series of dilutions ranging from 200, 300, 400 to $500 \mathrm{ppm}$. The solutions were prepared by the addition of $0.05 \mathrm{ml}$ of ethanol (for clear solution). The solutions were continuously stirred for one hour with the blunt end of a glass rod for complete dissolution of nanoparticles in the media. The solutions turned brownish in colour and were kept as such overnight. Thereafter they were ready for the experiment.

\section{Larvicidal activity}

Larvicidal activity was determined with different doses viz. 200, 300, 400 and 500 ppm of nanoparticle solution with the addition of $0.05 \mathrm{ml}$ ethanol for cleanness of the solution. The stock solution was prepared and different doses were applied on second instar larvae, which were on the surface of maizeleaves. The prepared nanomaterial solutions were then sprayed uniformly over the entire surface of the leaves. Ten second instar larvae of $M$. separata were released onto treated leaves. The first observations were made after $20 \mathrm{~min}$ of surface treatment with 200, 300, 400 and 500 ppm. Another control diet was maintained where leaves were treated with distilled water with $0.05 \mathrm{ml}$ of ethanol. Larvae were provided with fresh treated maize leaves every $24 \mathrm{~h}$. Observations were taken from the first day onwards. Larval mortality was recorded at $24 \mathrm{~h}$ intervals.

\section{Statistical analysis}

Statistical analysis was performed using SPSS version 20.0 for Windows. The larval mortality data were analysed using one way ANOVA to compare the effects of the treatments. Significant differences between treatments were determined using LSD test at 5\% level.

\section{Results and Discussion}

Silver nanoparticles synthesised from $T$. indicum leaves exhibited unique optical properties due to the possessions of surface plasmon resonance (SPR). Silver nanoparticles showed more intense SPR at $445 \mathrm{~nm}$ (Fig. 1). The prepared nanoparticles initially remained colourless and later turned reddish brown - a characteristic of Ag NPs. After that, these nanoparticles showed no additional alterations in colour implying the achievement of response. This constancy resulted from a potential deference that develops from an antagonism of the reaction and also weak Van der Waals forces of attraction and electrostatic repugnance.

The XRD spectrum confirmed the crystalline characteristic pattern of the prepared Ag NPs and clear

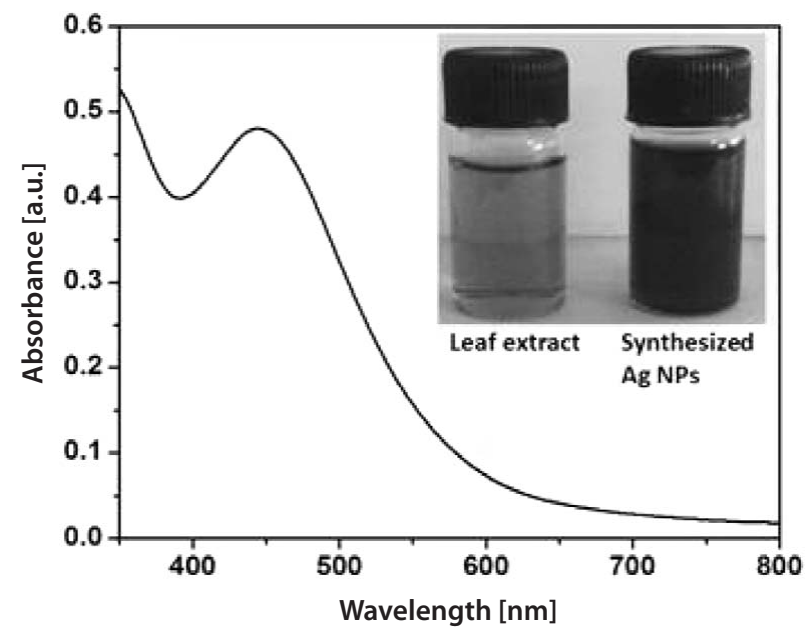

Fig. 1. Shows UV-vis spectra formation of the Ag NPs from leaf extract of Trichodesma indicum. Spectrum of Ag NPs formed due to addition of $T$. indicum leaf extract to silver nitrate solution 


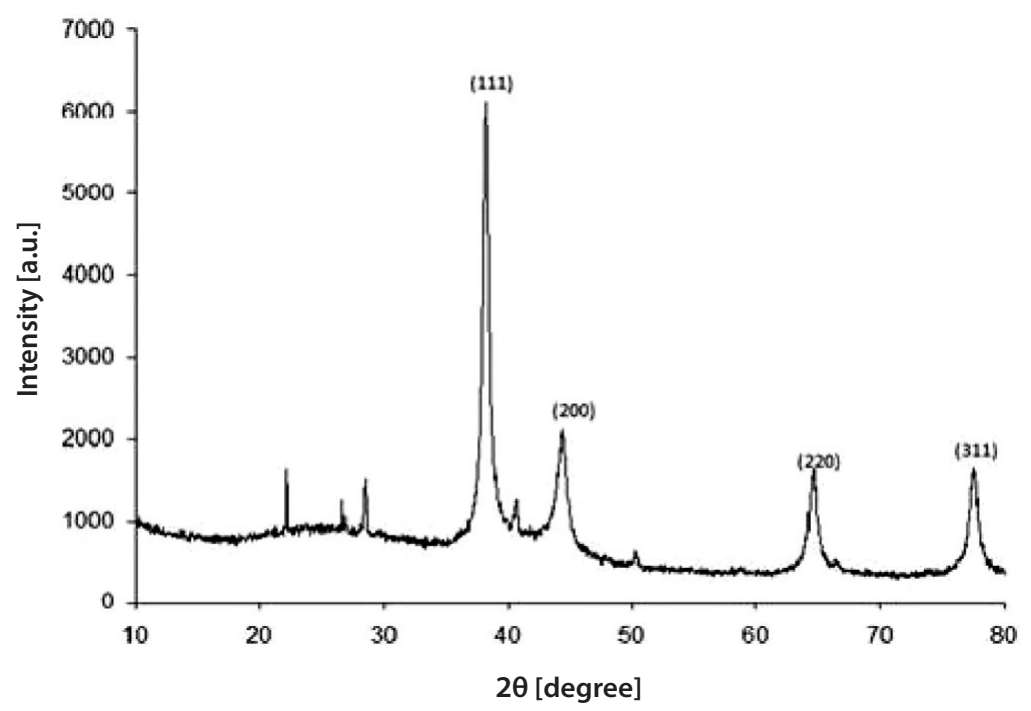

Fig. 2. X-ray diffraction (XRD) spectrum of silver nanoparticles (Ag NPs) extracted from Trichodesma indicum

peaks at $38.20^{\circ}, 44.39^{\circ}, 64.52^{\circ}$ and $77.43^{\circ}$ in the $2 \theta$ range corresponding to (111), (200), (220) and (311) Bragg's reflection planes were exactly indexed to the face centred cubic structure of silver nanoparticles (JCPDS 04-0783) (Fig. 2). Generally, the broadening of peaks in the XRD patterns of solids is attributed to particle size effects. Broader peaks signify smaller particle size and reflect the effects due to experimental conditions on the nucleation and growth of the crystal nuclei.

The TEM images of the prepared nanoparticles are shown in Figure 3. The spherical shaped nanoparticles were $20-50 \mathrm{~nm}$ in size, including the diameter. Most of the prepared nanoparticles were well spread out, while some were aggregated.

This study clearly demonstrated that Ag NPs possessed a tempting effect on the larval stage of M. separata. It has been reported that silver nanoparticles act as plant growth stimulators and reduce unwanted

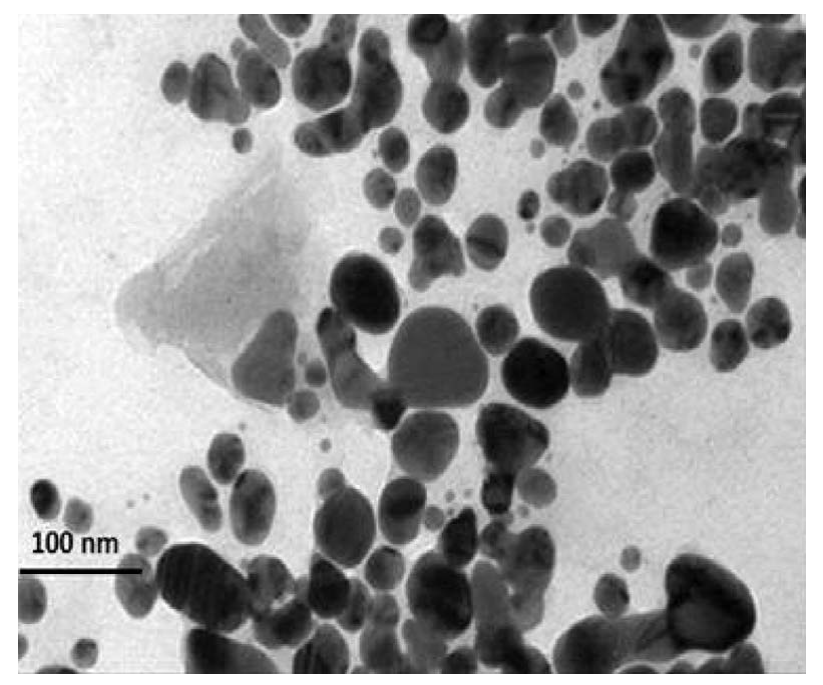

Fig. 3. TEM image of Ag NPs extracted from Trichodesma indicum microorganisms in soils and hydroponic systems (Sharon et al. 2010). Moreover, it may be mentioned here that silver was usually used as an antimicrobial agent in early civilizations. Silver nitrate has been used extensively due to its broad spectrum and multiple modes of antimicrobial activity in nature (Wei et al. 2009). Ag NPs are the most studied and utilized nanoparticles in bio-systems because of their strong inhibitory effect on certain diseases (Kim et al. 2008). Moreover, it is recognized that there is antifungal efficacy of a colloidal nanosilver solution against rose powdery mildew (Jo et al. 2009). Various forms of Ag NPs have been tested to examine their antifungal activity especially on two plant pathogenic fungi: Bipolaris sorokiniana and Magnaporthe grisea. In recent studies (in vitro and in vivo) on the efficacy of Ag NPs against powdery mildew before and after a disease outburst in plants under diverse cultivation circumstances, there was significant inhibition of the growth of fungal hyphae with the Ag NPs (Lamsal et al. 2011; Alghuthaymi et al. 2015; Megeed et al. 2015). Therefore, metal nanoparticles could be an improved option for insecticides. It has been reported that nanomaterials possess insecticidal properties ( $\mathrm{Si}-$ monian et al. 2005; Biju 2007; Rai et al. 2012; Chakravarthy et al. 2012). Furthermore, metal nanoparticles are essential components of new biosensors and self-assembled nanodevices (Levy et al. 2006; Hsing et al. 2007; Bhattacharyya et al. 2010).

In this study, Ag NPs caused considerable mortality at all treatment concentrations of second larval instars of M. separata (Table 1, Fig. 4). Mortalities of $46.67 \%$ $( \pm 6.67)$ and $83.33 \%( \pm 3.33)$ were achieved at 200 and $300 \mathrm{ppm}$ concentrations, respectively, on the fourth day of treatment. At $400 \mathrm{ppm}$ concentration, the mortality was $46.67 \%( \pm 3.33), 76.67 \%( \pm 8.81)$ and $100 \%$ $( \pm 0.00)$ on the second, third and fourth days, respectively. At $500 \mathrm{ppm}$ concentration, mortality reached 
Table 1. Effect of different concentrations of Ag NPs on 2nd larval instar of Mythimna separata after treatment

\begin{tabular}{ccccc}
\hline \multirow{2}{*}{$\begin{array}{c}\text { Treatment } \\
{[\text { ppm }]}\end{array}$} & \multicolumn{4}{c}{ Percentage of larval mortality days after treatment* } \\
\cline { 2 - 5 } & 1 st & 2nd & 3rd & 4th \\
\hline 200 & $0.0( \pm 0.00) \mathrm{a}$ & $0.0( \pm 0.00) \mathrm{a}$ & $23.34( \pm 3.33) \mathrm{a}$ & $46.67( \pm 6.67) \mathrm{a}$ \\
300 & $0.0( \pm 0.00) \mathrm{a}$ & $26.66( \pm 3.33) \mathrm{b}$ & $46.67( \pm 3.33) \mathrm{b}$ & $83.33( \pm 3.33) \mathrm{b}$ \\
400 & $0.0( \pm 0.00) \mathrm{a}$ & $46.67( \pm 3.33) \mathrm{c}$ & $76.67( \pm 8.81) \mathrm{c}$ & $100.0( \pm 0.00) \mathrm{c}$ \\
500 & $16.66( \pm 3.33) \mathrm{b}$ & $66.67( \pm 6.67) \mathrm{d}$ & $100.0( \pm 0.00) \mathrm{d}$ & - \\
\hline Control & 0.0 & 0.0 & 0.0 & 0.0 \\
\hline
\end{tabular}

* mean of 10 larvae/replication/treatment; figures in parentheses are standard error ( $\pm \mathrm{SE})$; means followed by same letters in each column are not significantly different by LSD at $5 \%$

$16.66 \%( \pm 3.33), 66.67 \%( \pm 6.67)$ and $100 \%( \pm 0.00)$ on the first, second and third days of treatment, respectively. When the data were subjected to ANOVA (Table 1), there were statistically significant differences between the treatments required for $50 \%$ mortality of the larvae. On the first, second and third days of treatment, the 400 and $500 \mathrm{ppm}$ concentrations produced significantly higher mortality than 200 and $300 \mathrm{ppm}$ treatments. Moreover, on the fourth day 300 and 400 ppm produced higher mortality than $200 \mathrm{ppm}$ treated concentration.
At a lower concentration of Ag NPs, the behaviour of the larvae was normal on the first day. At the highest concentration (500 ppm), feeding was reduced, larvae had sluggish movement and were black on the first day after treatment (Fig. 4b). On the second day after treatment, the larvae became stiff (Fig. 4c) and on the third day lysis of the larvae tissues was observed at the same concentration (500 ppm) (Fig. 4d). There was no mortality of the insects treated with distilled water, with $0.05 \mathrm{ml}$ of ethanol, in the control experiment (Fig. 4a). The above experiment clearly established that Ag NPs
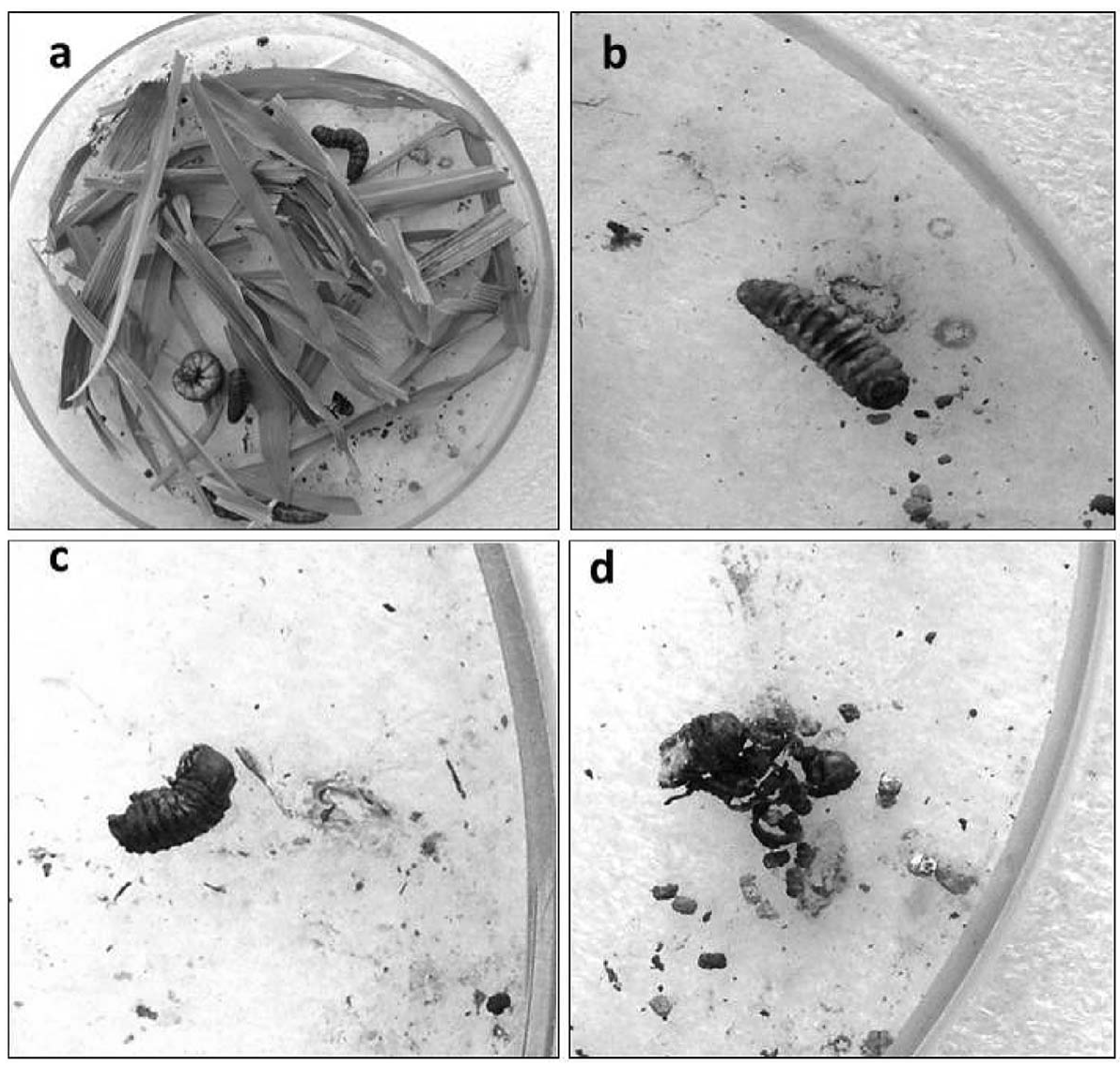

Fig. 4. Larvicidal experiment: a - Mythimna separata larvae in the control, $b-2 n d$ instar M. separata larva on 1st day after treatment with 500 ppm concentration, c - 2nd instar M. separata larva on 2nd day after treatment with 500 ppm concentration, $d-2$ nd instar M. separata larva on 3rd day after treatment with 500 ppm concentration 
should be tested at concentrations higher than $300 \mathrm{ppm}$ to determine the effective dose for $50 \%$ larval mortality. Recent studies demonstrated that Ag NPs induce embryonic injuries and reduce survival in zebra fish Danio rerio (Asharani et al. 2008; Griffitt et al. 2008). Moreover, nanosilver is also toxic in mammalian systems (Chen and Schluesener 2008). Therefore, our results clearly indicate that the proposed green silver nanomaterials have a tremendous effect on $M$. separata that leads to mortality at specific doses. Toxicity occurs because $\mathrm{Ag}^{+}$ions are released from the surface of the nanoparticle by oxidation processes and interact with biological molecules (e.g. insect proteins) upon entering the insect physiological processes (Park et al. 2010). Ag NPs are also known to interact with thiol groups of proteins and endorse their denaturation (Johnston et al. 2010), thus leading to larval mortality. It may be due to necrosis of the said insect cell that leads to mortality of the targeted insect pests. However the actual mechanism of toxicity is inadequately understood and more experiments are needed in this direction. This is the first report about the control of larvae of $M$. separata with Ag NPs.

\section{Conclusions}

We have developed a fast, eco-friendly and convenient method for biogenic synthesis of Ag NPs from silver nitrate using T. indicum at room temperature. From the experiment it can be concluded that Ag NPs, 20$50 \mathrm{~nm}$ in size, obtained from T. indicum possess good larvicidal activity against $M$. separata. The maximum mortality (100\%) was produced at a concentration of $500 \mathrm{ppm}$ within the shortest period of time, i.e. on the third day after treatment. Therefore, these Ag NPs can be an important component of an integrated pest management programme against $M$. separata.

\section{References}

Abdallah I.S., Abou-Yousef H.M., Fouad E.A., Kandil M.A 2016. The role of detoxifying enzymes in the resistance of the cowpea aphid (Aphis craccivora Koch) to hiamethoxam. Journal of Plant Protection Research 56 (1): 67-72. DOI: https://doi.org/10.1515/jppr-2016-0010_

Alghuthaymi M.A., Almoammar H., Rai M., Said Galiev E., Abd-Elsalam K.A. 2015. Myconanoparticles: synthesis and their role in phytopathogens management. Biotechnology and Biotechnological Equipment 29 (2): 221-236. DOI: https:// doi.org/10.1080/13102818.2015.1008194

Asharani P.V., Wu Y.L., Gong Z.Y., Valiyaveettil S. 2008. Toxicity of silver nanoparticles in zebrafish models. Nanotechnology 19: 1-8. DOI: 10.1088/0957-4484/19/25/255102

Bhattacharyya A., Bhaumik A., Usha R.P., Mamdal S., Epidi T.T. 2010. Nanoparticles - A recent approach to insect pest control. African Journal of Biotechnology 9 (24): 3489-3493. Available online at: http://www.academicjournals.org/AJB
Bhattacharyya A., Prasad R., Buhroo A.A., Duraisamy P., Yousuf I., Umadevi M., Bindhu M.R., Govindarajan M., Khanday A.L. 2016. One-pot fabrication and characterization of silver nanoparticles using Solanum lycopersicum: An eco-friendly and potent control tool against rose aphid, Macrosiphum rosae. Journal of Nanoscience 2016, 7 pp. DOI: https://doi.org/10.1155/2016/4679410_

Biju V. 2007. Quantum dot-insect neuropeptide conjugates for fluorescence imaging, transfection, and nucleus targeting of living cells. Langmuir 23 (20): 10254-10261. DOI: https:// doi.org/10.1021/la7012705

Chakravarthy A.K., Bhattacharyya A., Shashank P.R., Timothy T., Epidi Doddabasappa B., Mandal S.K. 2012. DNA-tagged nano gold: A new tool for the control of the armyworm, Spodoptera litura Fab. (Lepidoptera: Noctuidae). African Journal of Biotechnology 11 (38): 9295-9301. DOI: https:// doi.org/10.5897/ajb11.883.

Chen H., Yada R. 2011. Nanotechnologies in agriculture: New tools for sustainable development. Trends in Food Science and Technology 22 (11): 585-594. DOI: https://doi. org/10.1016/j.tifs.2011.09.004

Chen X., Schluesener H.J. 2008. Nanosilver: a nanoproduct in medical application. Toxicology Letters 176 (1): 1-12. DOI: https://doi.org/10.1016/j.toxlet.2007.10.004

Chowdappa P., Gowda S. 2013. Nanotechnology in crop protection: Status and scope. Pest Management in Horticultural Ecosystems 19 (2): 131-151.

Ensaf S.I.M., Inaam A.E., Mana H.E. 2016. Outbreak of oriental yellow scale insect, Aonidiella orientalis (Newstead) (Homoptera: Diaspididae), on neem in Sudan. Bulletin OEPP/EPPO Bulletin 46 (1): 125-128. DOI: https://doi. org/10.1111/epp.12264

Griffitt R.J., Luo J., Gao J., Bonzongo J.C., Barber D.S. 2008. Effects of particle composition and species on toxicity of metallic nanomaterials in aquatic organisms. Environmental Toxicology and Chemistry 27 (9): 1972-1978. DOI: https:// doi.org/10.1897/08-002.1

Hallberg K. 2010. Towards a responsible research in nanoscience and nanotechnology. Pasi Nano-Bio 1-47.

Harper S. 2010. New approaches needed to gauge safety of nanotech based pesticides, researchers urge. Physics and Chemistry 4 (33): 2010-2012.

Hsing I-M., Xu Y., Wenting Z.W. 2007. Micro and nanomagnetic particles for applications in biosensing. Electroanalysis 19 (7-8): 755-768. DOI: https://doi.org/10.1002/ elan.200603785

Ishiwaka R., Masuda Y. 2008. Possible biological control of the armyworm by the harvest mouse. Grassland Science 54 (1): 52 56. DOI: https://doi.org/10.1111/j.1744-697x.2008.00105.x

Jampilek J., Kralova K. 2016. Application of nanotechnology in agriculture and food industry, its prospects and risks. Ecological Chemistry and Engineering S. 22 (3): 321-361. DOI: https://doi.org/10.1515/eces-2015-0018

Jo Y-K., Kim B.H., Jung G. 2009. Antifungal activity of silver ions and nanoparticles on phytopathogenic fungi. Plant Disease 93 (10): 1037-1043. DOI: https://doi.org/10.1094/ pdis-93-10-1037.

Johnston C.T. 2010. Probing the nanoscale architecture of clay minerals. Clay Minerals 45 (3): 245-279. DOI: https://doi. org/10.1180/claymin.2010.045.3.245

Johnston H.J., Hutchison G., Christensen F.M., Peters S., Hankin S. 2010. A review of the in vivo and in vitro toxicity of silver and gold particulates: particle attributes and biological mechanisms responsible for the observed toxicity. Critical Reviews in Toxicology 40 (4): 328-46. DOI: https://doi. org/10.3109/10408440903453074

Kim H.S., Kang H.S., Chu G.J., Byun H.S. 2008. Antifungal effectiveness of nanosilver colloid against rose powdery mildew in greenhouses. Solid State Phenomena 135: 15-18. DOI: https://doi.org/10.4028/3-908451-48-5.15

Lamsal K., Kim S.W., Jung J.H., Kim Y.S., Kim K.S., Lee Y.S. 2011. Inhibition effects of silver nanoparticles against powdery 
mildews on cucumber and pumpkin. Mycobiology 39 (1): 26-32. DOI: https://doi.org/10.4489/myco.2011.39.1.026_

Levy R., Zhenxin W.Z., Duchesne L., Doty R.C., Cooper A.I., Brust M., David G., Fernig D.G. 2006. A generic approach to mono functionalized protein like gold nanoparticles based on immobilized metal ion affinity chromatography. ChemBioChem 7 (4): 592-594. DOI: https://doi.org/10.1002/ cbic. 200500457

Li F.B., Wang W., Zhang H.X., Shen W.F., Xu X.Y., Chen J.E., Meng Z.Q. 2015. Complete mitochondrial genome of the oriental armyworm Mythimna separata (Walker) (Lepidoptera: Noctuidae). Mitochondrial DNA 26 (6): 881-882. DOI: http://dx.doi.org/10.3109/19401736.2013.861441

Megeed M.S., Galal OLA A., Abdel-Razek M.M. 2015. Phylogenetic relationship of an invasive drosophilid, Zaprionus indianus and closely related species of drosophilidae (diptera) based on esterase patterns. Egyptian Journal of Genetics and Cytology 44 (2): 281-290.

Park E. J., Yi J., Kim Y., Choi K., Park K. 2010. Silver nanoparticles induce cytotoxicity by a Trojan-horse type mechanism. Toxicology In Vitro 24 (3): 872-878. DOI: https://doi. org/10.1016/j.tiv.2009.12.001

Prabha D., Nimisha S., Velmurugan P., Sivakumar S. 2015. Phytosynthesis of silver nanoparticles using leaf extract of Trichodesma indicum and its application in removal of dyes from aqueous solutions. Science and Engineering Research Board, New Delhi, Sponsored by National Conference on Applications of Nanotechnology in Environmental Remedation. 11-16.

Prasad R. 2014. Synthesis of silver nanoparticles in photosynthetic plants. Journal of Nanoparticles 2014, 8 pp. DOI https://doi.org/10.1155/2014/963961

Prasad R., Kumar V., Prasad K.S. 2014. Nanotechnology in sustainable agriculture: present concerns and future aspects. African Journal of Biotechnology 13 (6): 705-713. DOI: https:// doi.org/10.5897/ajbx2013.13554

Prasad R., Pandey R., Barman I. 2016. Engineering tailored nanoparticles with microbes: quo vadis. WIREs Nanomedi- cine and Nanobiotechnology 8 (2): 316-330. DOI: 10.1002/ wnan.1363.

Rai M.K., Deshmukh S.D., Ingle A.P., Gade A.K. 2012. Silver nanoparticles: the powerful nanoweapon against multidrug-resistant bacteria. Journal of Applied Microbiology 112 (5): 841852. DOI: https://doi.org/10.1111/j.1365-2672.2012.05253.x_

Rashid M., Khan R.A., Zhang Y. 2013. Physiological and population responses of armyworm Mythimna separata (Lepidoptera: Noctuidae) to a sub lethal dose of Cantharidin-AC. Journal of Economic Entomology 106 (5): 2177-2182. DOI: https://doi.org/10.1603/ec13089

Regnault-Roger C., Philogene B., Vincent C. 2005. Biopesticides of Plant Origin. Lavoisier, France, 313 pp.

Sharma H.C., Davies J.C. 1982. The oriental armyworm, Mythimna separata: distribution, biology and control: a literature review. Miscellaneous Report No. 59. Research Report. Overseas Development Administration, Wrights Lane, London, United Kingdom.

Sharon M., Choudhary A. Kr., Kumar R. 2010. Nanotechnology in agricultural diseases and food safety. Journal of Phytology 2 (4): 83-92. Available online: www.journal-phytology.com

Simonian A.L., Good T.A., Wang S.S., Wild J.R. 2005. Nanoparticle-based optical biosensors for the direct detection organophosphate chemical warfare agents and pesticides. Analytica Chimica Acta 534 (1): 69-77. DOI: https://doi. org/10.1016/j.aca.2004.06.056

Wang L., Hui C., Sandhu H.S., Li Z., Zhao Z. 2015. Population dynamics and associated factors of cereal aphids and armyworms under global change. Scientific Reports 5 (1). DOI: https://doi.org/10.1038/srep18801

Wei D., Sun W., QianYe W.Y., Ma X. 2009. The synthesis of chitosan-based silver nanoparticles and their antibacterial activity. Carbohydrate Research 344 (17): 2375-2382. DOI: https://doi.org/10.1016/j.carres.2009.09.001

Zhu F., Lavine L., O’Neal S., Lavine M., Foss C., Walsh D. 2016. Insecticide resistance and management strategies in urban ecosystems. Insects 7 (1): 2. DOI: https://doi.org/10.3390/ insects7010002 